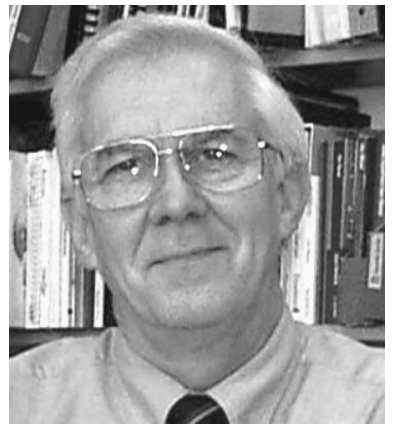

\section{Fellow of the SPIE}

It was with a great deal of pride and delight that I watched the induction of the new SPIE Fellows at the Annual Meeting in San Diego some weeks ago. The certificates were presented in the presence of an overflow crowd at the annual awards banquet in San Diego on July 22. Among the 21 SPIE Fellows that were honored, there were new Fellows from Singapore, Russia, Japan, and Poland. The 1998 SPIE Fellows are listed below.

Over the past few years I have had the privilege of serving on the Fellows committee and chairing it for one year. This year's committee was made up of Bob Hilbert as chair along with Jim Trolinger, Dan Vukobratovich, Jim Wyant, and myself. While it is a considerable responsibility and takes some time, the effort is certainly worth it. Even as I rejoiced in the recognition of this number of worthy scientists and engineers, I am mindful that we, all the members of SPIE, should be doing a better job than we are at present.

The requirements for elevation of an SPIE member are listed in the Bylaws. Members can find a copy in the Members Guide sent to all active members early each year. Briefly, any member can nominate another member for Fellow. However, there must be two recommendations from current Fellows of the Society.

The bylaws of SPIE permit $5 \%$ of the voting membership to be elevated to the level of Fellow. Right now there are about 300 active Fellows out of a total membership of 14,000 . Thus the number of Fellows is only about $2 \%$ of the membership. So there is plenty of room to recognize achievement in our society. And there are, in my opinion, plenty of our members who should be recognized. So . . . what's the problem?

There are several, really. One is that there is a need for members to take the initiative by submitting applications for other members they feel should be recognized by promotion to Fellow status. This, of course, requires additional work that should not be underestimated. In addition to obtaining a resume of the candidate, the proposer has to line up one additional Fellow, if he or she is a Fellow, or two, if not. And then there is always the possibility that the Fellows committee may not vote to endorse the can- didate, so that there is no guarantee that the work will be rewarded.

Two additional problems can be traced to the same source: the fact that the nomination and selection of Fellows are done by current Fellows. Let's take the nomination process first. Recognition of work in newer fields of optical engineering can be difficult because there are very few (or no) Fellows in these fields. This makes it hard to even get the nomination process started, since recommendations from two current Fellows are required in the Bylaws. This is a classic chicken and the egg dilemma.

The other problem is found within the selection process. The evaluation of an application by the Fellows committee is based on three criteria: technical accomplishments, service to SPIE, and service to the optics community, weighted as $3: 2: 1$. This weighting provides that both a distinguished technical effort and exemplary service to the community count toward the evaluation of the candidate's record. Evaluations are done by a number of SPIE Fellows, who evaluate and rank each applicant. The members also indicate their familiarity with the technical specialty of the candidate, so that more weight can be given to those most familiar with the area in which the candidate has worked. A telephone conference of the committee is used to determine the final list based on committee averages and rankings. Again, there is the problem of familiarity of old Fellows with new fields.

With all this, one is a little amazed that 21 Fellows were promoted at the Annual Meeting! To those that contributed to their selection, I wish to offer thanks. But what can be done to recognize more of our deserving members? It might be suggested that the Fellows committee take a more pro-active stance toward promoting applications. This would be a bad idea. A committee evaluating Fellows applications should not encourage submissions to it because it would give the appearance of prior approval, when none may be forthcoming. The committee is an instrument for evaluation and selection, not promotion. I also believe the Bylaws should be kept as they are. There are better ways to solve the problem.

I think the following directions in the space of a few years can increase the number of SPIE Fellows to better reflect the amazing accomplishments and breadth of fields of our membership. On an individual basis, the leadership 
of SPIE needs to make members more aware of the opportunity to recognize excellent work. This might be done by publishing the requirements and forms on the home page of the SPIE web site along with a notice at specific times. A short e-mail message to members directing them to the web site would provide nearly universal coverage of our membership.

One action that any proposer can take to increase the possibility that his or her candidate will be elected is to provide complete information in the nomination package. As I have found from serving on the committee, a number of nominees were not promoted because of a lack of information. It is particularly important to describe the significance of a candidate's technical accomplishments if they are in a new discipline that the committee may not be familiar with.

There are 22 active Technical Working Groups in SPIE. It would be in the interests of these working groups to promote persons within their field as part of their ongoing activities. A small subcommittee of three members could be charged with scanning the membership roster of the group, suggesting candidates, and organizing the required effort to support the applications. This would be particularly valuable in those fields in which the number of Fellows is small. Considering the small number of women listed among the Fellows, the new working group, Women in Optics, could provide valuable assistance in rectifying an obvious, to me anyway, deficiency.

Finally, at the Committee level the process can be improved. When assembling the Fellows committee the Chair should ask one or two of the newer Fellows, particularly those in non-traditional areas, to serve. This would provide more breadth to the evaluation process. While the process will never be perfect, it can be continually improved to provide the recognition that members of this interesting and dynamic society deserve.

Donald C. O'Shea Editor

\section{New Fellows Elected to SPIE}

Twenty-one members have been selected by the Fellows Committee for promotion to the grade of Fellow of the Society. These new Fellows were officially presented and promoted during SPIE's Annual Meeting in San Diego, California, in July. Fellows elected to the Society are individuals of distinction who have made significant technical and scientific contributions in optics and optoelectronics. The new Fellows include:
Anand Asundi
David L. Begley
W. Thomas Cathey
Katherine Creath
Edward John Delp III
Yuri N. Denisyuk
Jan Dubowski
Robert A. Fisher

\author{
Douglas S. Goodman \\ James A. Harrington \\ Satoshi Ishihara \\ Suganda Jutamulia \\ Gary Kammerman \\ Manouchehr E. Motamedi \\ Jerry Earl Nelson \\ Krzysztof Patorski \\ Michael T. Postek \\ Nabeel A. Riza \\ Chandra Sekhar Roychoudhuri \\ James A. Smith \\ Austin L. Vick \\ The 1998 Fellows Committee is chaired by Robert S. \\ Hilbert, Optical Research Associates. Committee members \\ include Donald O'Shea, James Trolinger, Daniel Vuko- \\ bratovich, and James Wyant. SPIE Fellows number more \\ than 300 researchers and engineers advancing optics and \\ photonics technologies worldwide.
}

